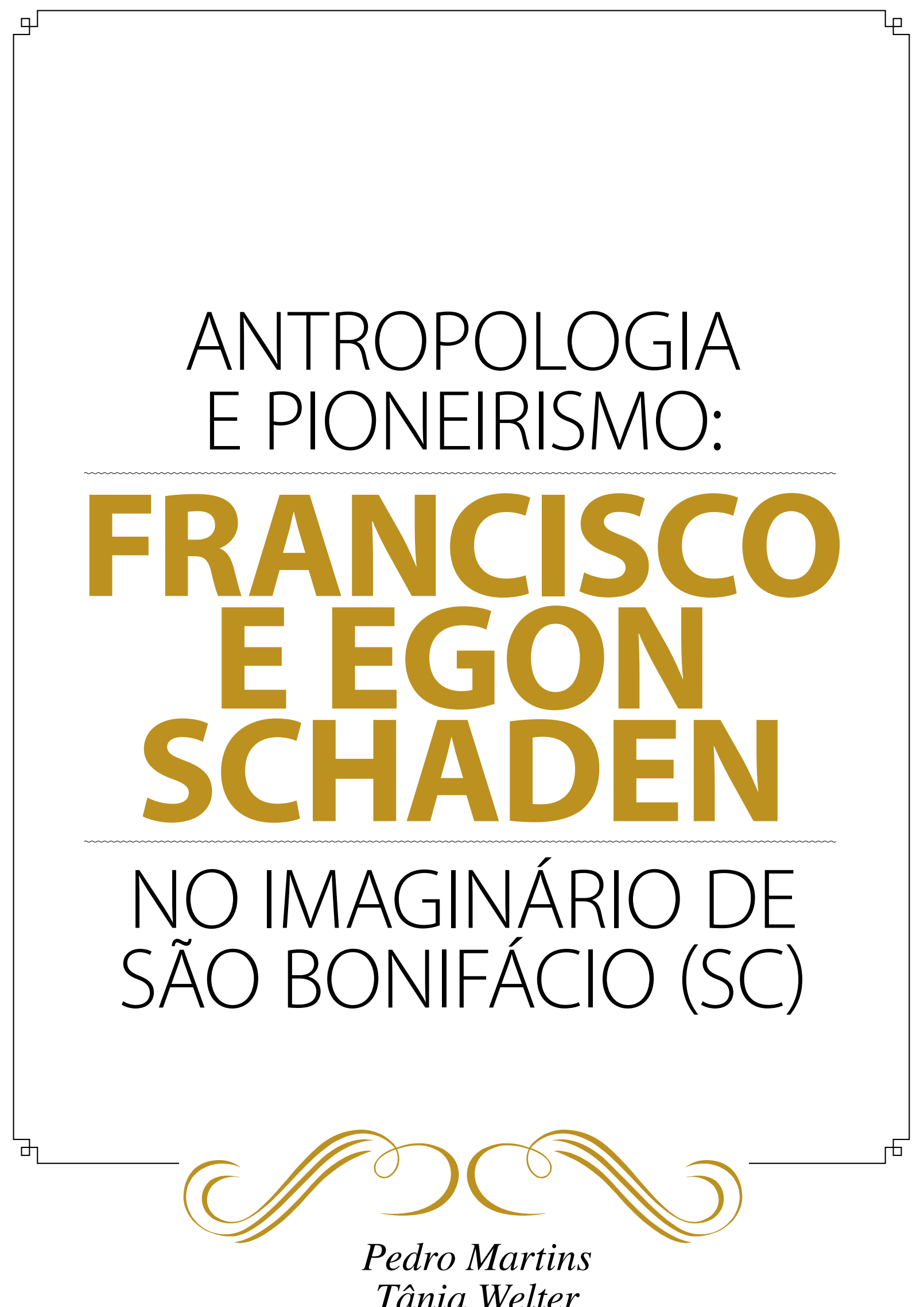

Tânia Welter 


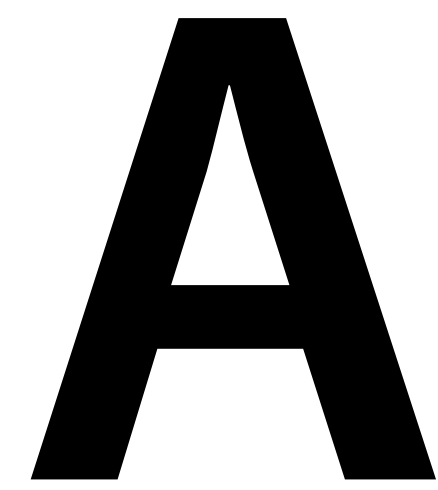

pequena cidade de São Bonifácio, incrustada nas encostas da Serra Geral de Santa Catarina, a 70 quilômetros de Florianópolis, é um lugar de muitas curiosidades para qualquer viajante. Sua população, dentre a qual registra-se a presença de descendentes de colonos originários da cidade de Trier, Westfália, mantém os traços característicos dos imigrantes alemães chegados no século XIX e cultiva uma história em grande medida resultante da ação dos pioneiros e das sucessivas gerações de cidadãos comuns sempre ciosos de suas origens. É nesse contexto que o antropólogo minimamente familiarizado com a literatura indigenista é surpreendido com a presença da família Schaden, a mesma do antropólogo e indigenista Egon Schaden, mas também do pioneiro Francisco Schaden, seu pai.

PEDRO MARTINS

é antropólogo

e professor

da Universidade

do Estado de Santa

Catarina (Udesc).

\section{TÂNIA WELTER}

é antropóloga

e pós-doutoranda

na Universidade

Federal de Santa

Catarina (UFSC).

Uma versão preliminar deste texto foi apresentada emforma de comunicação à IX Reunião de Antropologia doMercosul (RAM), realizada em Curitiba no período de 10 a 13 de julho de 2011.

1 Realizadoem parceria com Mauro De Bonis Almeida Simões e Esdras Pio Antunes da Luz, o projeto de pesquisa "A dinâmica das redes de sociabilidades no processo de desenvolvimento territorial sustentável - um estudo de caso em São Bonifácio/ $\mathrm{SC}^{\prime \prime}$ recebeu apoio financeiro do CNPq/ Fapesc/Udescatravés do Edital 04/2007/ Fapesc.
Este texto, resultante de levantamento bibliográfico e da observação feita em campo ao longo de um projeto de pesquisa ${ }^{1}$, trata de apresentar elementos para a compreensão da formação social de São Bonifácio, levanta a origem social e a trajetória de Francisco e Egon Schaden e busca desenvolver uma hipótese sobre a colaboração científica entre pai e filho. Embora Francisco Schaden, em termos de formação acadêmica, nunca tenha passado de um professor primário, o autodidatismo e a colaboração com seu filho Egon, um dos pioneiros da antropologia no Brasil, o levaram a registrar uma produção científica que deixou marcas pelo menos na história de São Bonifácio. Juntos, os dois pioneiros contribuem de maneira importante para a construção do imaginário dessa antiga colônia alemã. A importância atribuída a Egon Schaden na construção da antropologia no Brasil é similar à importância atribuída a seu pai Francisco Schaden como pioneiro na estruturação de São Bonifácio.

Não se pretende fazer aqui uma revisão bibliográfica sobre o tema, mas estruturar uma hipótese de trabalho na qual se sustenta que a obra científica de Francisco Schaden foi em grande medida favorecida por Egon Schaden através de sua intervenção direta ou de articulações decorrentes de suas rela- ções pessoais - como no caso da colaboração de Francisco Schaden na obra de Emílio Willems. Nesse sentido, apenas como indicador da hipótese em questão, propõe-se que Willems, Schaden pai e Schaden filho constituem, de certa forma, um triângulo científico em que Egon atua como intermediário, tendo sido aluno e assistente de Emílio Willems.

A produção deste texto é orientada pela noção de imaginário. Toma-se aqui o conceito de imaginário na perspectiva adotada por Durand (1997, p. 14), que define imaginário como o "[...] conjunto das imagens que constitui o capital pensado do Homo sapiens". Diferentemente de Deleuze (1992), para quem $\mathrm{o}$ ato de imaginar corresponde à criação ou construção de imagens, Durand (1997, p. 432) afirma que "[...] o imaginário não só se manifestou como atividade que transforma o mundo, como imaginação criadora, mas sobretudo como transformação eufêmica do mundo, como intelectus sanctus, como ordenança do ser às ordens do melhor". Com ele concorda Castoriadis (1993) quando afirma que o que conhecemos como "realidade" e "racionalidade" são produtos do imaginário.

Espera-se, assim, demonstrar como o universo de São Bonifácio tem sido marcado pela imaginação criadora acerca de alguns de seus personagens. 


\section{SÃO BONIFÁCIO, HISTÓRIA \\ E FORMAÇÃO SOCIAL}

Localizado nas encostas da Serra Geral, a 80 quilômetros da capital do estado de Santa Catarina, São Bonifácio integra a Região Metropolitana de Florianópolis. O município possui características de pequeno porte, tendo o censo do IBGE de 2010 registrado a presença de 3.008 habitantes $^{2}$. O acesso ao município de São Bonifácio se dá pela Rodovia BR 282, que parte de Florianópolis em direção ao sul e logo sobe a encosta da Serra Geral. No município de Águas Mornas o acesso segue pela Rodovia SC 431, que teve a pavimentação asfáltica concluída em maio de 2004. O nome do município foi inspirado no santo padroeiro da Westfália, região alemã de origem da maioria dos primeiros imigrantes.

A origem do município de São Bonifácio está ligada à criação da Colônia Teresópolis, unificada com a Colônia Santa Isabel em dezembro de 1865. Partindo da ocupação inicial do Rio Cubatão, os imigrantes instalados na Colônia Teresópolis continuaram subindo as encostas e ocuparam a região do Rio Capivari e seus afluentes, alcançando São Bonifácio do Capivari o privilégio de distrito de paz em 1918. O distrito desmembra-se de Palhoça e alcança a condição de município em 23 de agosto de $1962^{3}$.

As colônias mencionadas ocuparam terras de difícil acesso, habitadas originalmente por grupos indígenas nômades, onde foram assentados imigrantes católicos e luteranos provenientes em sua maioria da região da Renânia e Westfália, na Alemanha, além de imigrantes de outras regiões da Alemanha que já se encontravam estabelecidos em outras partes do Brasil - como as fazendas de café em São Paulo.

A imigração alemã que dá origem a São Bonifácio insere-se no contexto das grandes migrações europeias que tiveram início no século XIX, entre o fim das guerras napoleônicas e o início da Primeira Guerra Mundial, que pode também ser caracterizado como o período que vai de 1815 a 1914. Dos cerca de 60 milhões de pessoas que deixaram a Europa no período, algo em torno de 5 milhões eram alemães, dirigindo-se a maioria para os Estados Unidos da América e o restante para outros países, como Canadá, Austrália, Argentina e Brasil. Dos imigrantes recebidos pelo Brasil no período de 1819 a 1947, 235.846 foram registrados, ao entrar no país, como alemães (Jochem, 2002, p. 19) ${ }^{4}$.

Além das guerras napoleônicas, outra causa subjacente ao quadro de migrações mencionadas é a Revolução Industrial na Europa. Quando a Revolução Industrial chega na Alemanha e os teares mecânicos substituem os trabalhadores, exacerba-se a situação de miséria que já assolava camponeses e trabalhadores urbanos. Conforme resgate de Jochem (2002, p. 21),

"Nas propriedades rurais, a terra já escasseava ao ser, a cada geração, exercido o direito de herança; $o$ artesão e o comerciante tinham suas atividades restritas pela concorrência; $\mathrm{o}$ surgimento do processo de industrialização não bastou para absorver toda a mão-de-obra excedente, de modo que o operário não via oportunidade de ascensão profissional".

No quadro descrito, a emigração de trabalhadores, tanto urbanos quanto rurais, respondia a uma estratégia de Estado para diminuir as inúmeras formas de pressão interna.

Do ponto de vista do Brasil, como país receptor de imigrantes, o processo também fazia parte de uma estratégia de Estado. $\mathrm{Na}$ perspectiva de Seyferth (1999, p. 279), "A colonização visava instalar no país agricultores livres e europeus, portanto brancos, [...] em áreas não ocupadas pela grande propriedade, num processo controlado pelo Estado" - embora em muitos casos fossem terras previamente ocupadas por grupos indígenas que passavam a ser combatidos para garantir a presença e a segurança dos colonos. $\mathrm{Na}$ opinião de Jochem (2002, p. 36), “o governo brasileiro pretendia, com a colonização baseada no regime de pequenas propriedades
2 Dado disponível em: http://www.censo2010.ibge.gov. $\mathrm{br} /$. Acessado em 22/5/2011. Na verdade, o município vem perdendo população desde a década de 1970. No censo de 1980, São Bonifácio contava com uma população de 3.530 caindo para $3.373 \mathrm{em}$ 1990 e 3.218 em 2000 A emigração para estudar-quase sempre sem retorno - é apenas uma das causas da depopulação. Talvez o fenômeno mais importante nesse sentidotenha sidoa revolu ção verde (ver Martini \& Garcia, 1987), cujas consequências ainda se fazem sentir.

3 A condição de distrito de pazé dada pela Lei Municipal de Palhoça número 271 , de 23 de setembro de 1918, enquanto a condição de municípioédada pela Lei Estadual número 840 , de 23 de agosto de 1962.

4 Deve-se atentar para a imprecisão desses númerosuma vezque as condições de identificação eram muito precárias. Por outro lado, a identificação dos imigrantes como alemães refere-se à cultura e não ao estado nacional. 
5 Segundo relato de Thecla Schaden Buss, Francisco Schaden chega ao Brasilacompanhado dos pais, Franz Schaden e Mathilde Verhey Schaden. O pai, do qual nunca mais se teria notícia, logo regressa à Alemanha, ao passo que a mãe, que já havia perdido os outros seis filhos para doenças, permanece no Brasil ao lado do filho, exercendoaprofissão de enfermeira e parteira por toda a sua vida.

6 Emjunhode2011 apenas Thecla, Siegfriede Luzia ainda estavam vivos.

7 Tendo nascido na Alemanha, informa esse autor, Francisco Schaden teria sido vítima de atos discricionários porpartedo Estado brasileiro impetrados contra alemães no Brasil desde o início da Segunda Guerra Mundial.

8 "Apontamentosparaa História doEsperanto em Santa Catarina". O manuscrito dessetexto compõe o acervo do Museu Francisco Schaden, em São Bonifácio. e trabalho livre, profundas mudanças sociais em curto e longo prazos", e esclarece:

"[...] entre os objetivos da política de colonização, estava o desejo de compor uma classe média rural integrada por imigrantes europeus locados em pequenas propriedades [...]. Nesse contexto, os alemães eram considerados bons agricultores, portanto ideais para povoar vazios demográficos no regime de pequena propriedade rural" (Jochem, 2002, p. 11).

Santa Catarina recebeu imigrantes alemães a partir de 1829 , os quais se instalaram inicialmente em São Pedro de Alcântara, na Grande Florianópolis, e, posteriormente, em outras regiões, como o Vale do Itajaí.

A Colônia de Teresópolis, que dará origem aos municípios de Águas Mornas e São Bonifácio, na Região da Grande Florianópolis, é implantada em 3 de junho de 1860.

Em 1895, a comunidade de São Bonifácio do Capivari fundou seu primeiro prédio escolar - entendido como uma escola particular. Em 1918, a escola se tornou pública, tendo Francisco Schaden como seu primeiro professor.

\section{TRAJETÓRIAS PIONEIRAS}

Para os propósitos deste texto, cabe traçar a trajetória dos pioneiros Francisco Schaden e Egon Schaden, intercalada por uma breve nota acerca de Emílio Willems.

Francisco Serafim Guilherme Schaden nasceu em Leipzig, Alemanha, em 19 de fevereiro de 1891. Chegou ao Brasil em $1910^{5}$, tendo passagem pela comunidade de Leopoldina, em Minas Gerais, Anitápolis e Löffelscheidt (município de Águas Mornas), em Santa Catarina, em 1912, antes de se instalar no lugar conhecido hoje como São Bonifácio. Casou-se com Catharina Roth, natural de Löffelscheidt, com quem teve onze filhos: Egon Francisco Willibald, Godwin Francisco Twisko, Eleonora Catharina Maria, Elmar Francisco José, Mathilda Catharina Maria, Thecla Catharina Olindina, Inocência Ca- tharina Maria, Francisco Vicente Ingo, Balduino Francisco José, Siegfried Francisco Wunibaldo e Luzia Catharina Adelina ${ }^{6}$.

Sua vida profissional como professor estendeu-se de 1912 a 1938 - quando foi aposentado compulsoriamente, segundo Jochem (1992) ${ }^{7}$, e passou a se dedicar com empenho a diferentes atividades científicas.

Paralelamente à sua atividade como professor na escola de São Bonifácio, Francisco Schaden atuou como organizador comunitário e ativista pela emancipação política de sua comunidade. Defendeu a criação do distrito de São Bonifácio e foi seu primeiro intendente distrital. Defendeu a criação do cartório local e foi seu primeiro escrivão. Sua qualificação escolar diferenciada e a limitação, nesse sentido, da maior parte dos seus conterrâneos fizeram com que exercesse os novos cargos criados. Atuou também no movimento pela construção da estrada de rodagem ligando São Bonifácio a Florianópolis. Foi botânico autodidata. Estudava as plantas com o propósito de ensinar sobre elas, mas também com o objetivo prático de produzir remédios naturais com os quais atendia seus conterrâneos. Organizou coleção de objetos mostrando a cultura material dos indígenas da região, em sua época ainda não completamente extintos. Voluntariamente organizou curso noturno de alfabetização de adultos décadas antes de essa atividade se tornar uma preocupação do poder público.

O aprendizado de línguas foi outra preocupação constante na vida do pioneiro Francisco Schaden. Além do português e do alemão (idiomas pátrios), seu neto Siegfried Schaden afirma que possuía bons conhecimentos de francês e latim e havia estudado as línguas internacionais esperanto, sdo e volo-pük. Pauli (2002), fazendo um apanhado da história do esperanto em Santa Catarina para o Congressso Universal do Esperanto (Fortaleza, 2002), registra como documento mais antigo sobre o tema no estado um trabalho inédito de Francisco Schaden ${ }^{8}$. Siegfried Schaden aponta ainda seus conhecimentos de línguas indígenas, que o levaram a escrever uma gramática e 
um dicionário tupis, um dicionário xokléng e documentar a língua kaingang.

Francisco Schaden deixou uma produção bibliográfica considerável, ainda que não se possa estabelecer uma unidade de gênero entre os diversos materiais disponíveis. Segundo Siegfried Schaden, Francisco Schaden iniciou a publicação de textos em jornais antes mesmo da Primeira Guerra Mundial. Sua estreia provavelmente teria ocorrido no jornal curitibano Ser Rompass, atividade que continuou no jornal Die Rundschou, de Brusque, e na revista Pindorama, fundada em São Paulo por Egon Schaden com o propósito de partilhar temas brasileiros com leitores alemães e da qual foi coeditor. $\mathrm{O}$ primeiro número da revista Pindorama foi lançado em 1937, mostrando que a colaboração científica entre pai e filho começou cedo.

Após sua aposentadoria dedica-se mais fortemente à produção escrita, registrando colaborações com o jornal $O$ Estado de $S$. Paulo, com as revistas Sociologia, Boletim Bibliográfico e a Revista do Arquivo Municipal, todos de São Paulo, além da Revista do Instituto Histórico e Geográfico de Santa Catarina e Atualidade, ambas de Florianópolis, e outros jornais dessa cidade. Parte dessa produção irá compor uma coletânea (Schaden, 1963) organizada e editada por Egon Schaden.

Merecem destaque, como trabalhos científicos, dois artigos de sua autoria, sobre a questão indígena, publicados na Revista de Antropologia (Schaden, 1953 e 1958), na época dirigida por Egon Schaden. Santos (2006, p. 25) qualifica esses artigos como "exemplos marcantes" de resultados da pesquisa antropológica em Santa Catarina. O artigo de 1958 foi reeditado em coletânea organizada por Egon Schaden (1972), que teve uma segunda edição em 1977. Na mesma linha apareceu o trabalho apresentado ao IX Congresso Brasileiro de Geografia, publicado como separata dos anais do evento (Schaden, 1940), abordando a história de São Bonifácio e outros relatos pitorescos. Para os propósitos deste texto é importante registrar como produção científica sua colaboração como etnógrafo na obra de Emílio Willems (1980)9 .
Francisco Schaden tornou-se membro do Instituto Histórico e Geográfico de Santa Catarina e era conhecedor de aspectos da astronomia - embora tenha preferido não investir nesse ramo de conhecimento. Dedicou-se, porém, à poesia, tendo deixado uma produção que revela seu bom humor e encanto pela natureza. Faleceu em São Bonifácio em 26 de dezembro de 1957, aos 67 anos.

\section{EGON, FRANCISCO E EMÍLIO WILLEMS}

A cooperação de Francisco Schaden na obra de Emílio Willems é um fator que só pode ser explicado pela intermediação de Egon Schaden. A obra A Aculturação dos Alemães no Brasil (Willems, 1980) registra o trabalho de cooperação entre os dois alemães, tendo Willems utilizado como suporte ao seu trabalho dados etnográficos coletados em campo por Francisco Schaden - embora o reconhecimento seja registrado apenas em notas de fim de texto ${ }^{10}$.

Emílio Willems nasceu em 1905 na Alemanha, onde se diplomou em economia pela Universidade de Berlim. Imigrado no Brasil, atuou no ensino secundário do Paraná e Santa Catarina antes de ingressar na Universidade de São Paulo, encaminhado pelo professor Fernando de Azevedo (Pereira, 1994). Tendo chegado à USP em 1936, Willems cumpre um papel pioneiro atuando na implantação e consolidação das disciplinas de sociologia e antropologia. Segundo afirma Pereira (1994, p. 250), "a Willems devem-se pesquisas de campo e reflexões que tiraram a antropologia feita no país de seu interesse apenas pelo biológico e pelo tribal e a colocaram como ciência preocupada com a análise e a interpretação de aspectos cruciais da sociedade complexa brasileira".

Com a obra A Aculturação dos Alemães no Brasil, Willems revela seu pioneirismo também ao abordar a imigração alemã como tema de pesquisa.
9 Trata-se, nesse caso da segunda edição da obra. A primeira edição é datada de 1946.

10 A contribuição de Francisco Schaden na referida obra aparece nas páginas 245 6, 255-6, 281, 311 e 360-1. 
11 Disponívelem: www. capitaldascachoeiras.com.br. Acessado em: 12/5/2011.

12 Especialmente para a temática do povo guarani, como destaca apropriadamente Meliá, S.J. (1991).

13 Toma-se aqui a $R e$ vista de Antropologia como uma referência da importância de Egon Schaden para a antropologia no Brasil.

\section{A ORIGEM SOCIAL DE EGON SCHADEN}

Egon Francisco Willibald Schaden nasceu em São Bonifácio (SC) em 4 de julho de 1913, primeiro filho de Francisco Schaden e Catharina Roth Schaden. Ao concluir o ensino primário em 1924, ocorre um evento que muda o seu destino de menino do mundo rural e alimenta o imaginário do pequeno município de São Bonifácio até os dias atuais.

Em visita a São Bonifácio, Adolfo Konder, governador do estado, hospedou-se na residência de Francisco Schaden, onde conheceu Egon, então com 12 anos, e lhe ofereceu uma bolsa de estudos para continuar sua formação em Florianópolis.

Sobrinho de Egon, Sigfried Schaden, em sua página sobre pessoas ilustres de São Bonifácio, ao falar dessa visita de Adolfo Konder, faz a seguinte anotação:

"Como era um dia chuvoso ele foi convidado a hospedar-se na residência dos Schaden, de forma que o professor Schaden pediu ao filho Egon que limpasse os sapatos do governador, que estavam sujos de barro devido ao acesso difícil à nossa localidade na época (a viagem havia sido feita a cavalo). Enquanto o menino lustrava os sapatos, o governador do Estado foi lhe fazendo algumas perguntas as quais foram prontamente respondidas. Então, impressionado com as respostas do menino, o Sr. Adolfo Konder perguntou ao professor Schaden como estava indo o menino nos estudos e este, por sua vez, respondeu que ele havia terminado a primeira fase em São Bonifácio mas que a família não tinha como custear seus estudos na capital"11.

No Ginásio Catarinense Egon cursou o colegial, o que o habilitou a ingressar na $\mathrm{Fa}$ culdade Paulista de Letras e Filosofia, onde cursou os dois primeiros anos de Filosofia, e logo na Faculdade de Filosofia, Ciências e Letras da Universidade de São Paulo, onde concluiu o curso e graduou-se em 1937, tendo Claude Lévi-Strauss como um de seus professores (Pereira, 1994, p. 249).
Na mesma USP, Egon Schaden realizou seus estudos pós-graduados e desenvolveu sua carreira profissional como professor de antropologia. Tornou-se o primeiro assistente de Emílio Willems na USP e contribuiu de maneira definitiva para o fortalecimento institucional da antropologia naquela universidade. Sua obra - teses e outros escritos está voltada para a compreensão da questão indígena ${ }^{12}$, servindo de base para seus cursos de etnologia.

Em 1953 Egon Schaden funda a Revista de Antropologia, uma grande contribuição à construção da antropologia brasileira. Na edição comemorativa dos cinquenta anos de fundação da revista, João Baptista Borges Pereira rememora, em entrevista concedida a Stélio Marras, a saga de Egon Schaden frente à criação e manutenção do periódico (Marras, 2003).

\section{EGON SCHADEN E A REVISTA DE ANTROPOLOGIA}

João Baptista Borges Pereira herdou, com a aposentadoria de Shaden, a cátedra de Antropologia. Pereira conta que herdou também, de Schaden, seus orientandos e a Revista de Antropologia. Para ele, a Revista de Antropologia deve sua existência a um "ato heroico" de Schaden. Segundo ele, "não foi um ato institucional, porque se dependesse da instituição não haveria a revista, nunca. Ele é que fundou a revista, ele que a idealizou" (Marras, 2003, p. 327). E acrescenta logo:

"[...] a Revista de Antropologia era de Schaden, não do Departamento, porque ela não era institucional, embora funcionasse como se fosse. Na verdade, tanto o Schaden quanto os demais que o rodeavam falavam da revista como 'a revista do Schaden'. Então, com a saída dele, ela passou a ser formalmente da USP, num momento em que havia um universo de pouquíssimos periódicos e revistas" (Marras, 2003, pp. 228-9).

Além da revista, Schaden deixou as bases para a criação da primeira pós-graduação em 
Antropologia, na década de 1970 (Marras, 2003, p. 228).

A Revista de Antropologia, afirma Pereira, "[...] serviu de importante canal mesmo para autores não propriamente da antropologia. Antonio Candido, Ruy Coelho, Florestan Fernandes e Otávio Ianni, por exemplo, publicaram nela. A Revista era aberta e era praticamente o único canal de comunicação" (Marras, 2003).

Aumentando a importância da revista, Pereira afirma que, além de ter toda a linha editorial pensada por Schaden, o fundador insistia no acolhimento de resultados de pesquisa, "mesmo que não fossem refinados do ponto de vista teórico. [...] acho que a Revista teve um papel importante na história da antropologia no Brasil na medida em que ele adotava, como princípio, estimular bastante a pesquisa de campo" (Marras, 2003, p. 329). Não obstante, para Pereira, Egon Schaden “já era naquele tempo um importante teórico da etnologia" (Marras, 2003), como o demonstrou em sua tese de livre docência ${ }^{14}$. A esse respeito afirma Meliá, S.J. (1991, p. 77):

“A síntese que apresentou em 1954 é a primeira de seu gênero e até hoje a única, em que os três grandes grupos de guaranis atuais são vistos em sua complexa realidade de analogias e diferenças, a partir de um trabalho de campo que ninguém antes havia empreendido de um modo tão amplo. [...] se tornou uma obra de consulta necessária para os estudiosos do guarani e uma referência obrigatória na história da etnologia brasileira".

O processo de produção da Revista de Antropologia demonstra não apenas a precariedade das condições da época, mas também o espírito que movia Egon Schaden como intelectual.

Afirma Pereira que "Schaden não só comprava o papel, mas reescrevia os artigos para deixá-los no ponto ideal; comprava selo, passava a língua, selava; e de ônibus levava aos poucos ao correio central, lá no Anhangabaú" (Marras, 2003, pp. 329-30). O editor da Revista de História, criada dois anos antes da Revista de Antropologia, comovido com o esforço de Schaden para levar em frente seu projeto editorial, garantia a ele o maquinário para a impressão, mas "Schaden tinha de dar o papel e, como não tinha verba, ele tirava do próprio bolso" (Marras, 2003, p. 330).

As consequências de tal empenho foram reveladas por Schaden a Pereira, segundo este, em um raro momento de confidências, no qual

“[...] disse-me que, quando olhava seus filhos, ficava pensando se havia feito bem ou se havia feito mal, porque muitos natais passaram sem ganhar presente, já que com o dinheiro dos presentes, que poderia comprar para eles - porque ele ganhava pouco - ele comprava papel para a Revista de Antropologia" (Marras, 2003).

Pereira (1994) conta que Egon Schaden aposentou-se da Universidade de São Paulo em 1967, com o propósito de assumir, na Alemanha, a cátedra de Etnologia da Universidade de Bonn, intento que, segundo Pereira, não logrou atingir em função de questões pessoais e familiares ${ }^{15}$.

Antes disso, no entanto, Schaden já havia se tornado, na opinião de Ribeiro (2003, p. 351), "uma das principais lideranças da antropologia brasileira no século XX".

Tendo regressado ao país, após um périplo acadêmico por uma dezena de países, Egon Schaden retornou à Universidade de São Paulo, dessa feita à Escola de Comunicações e Artes (ECA), onde permaneceu até sua morte, em $1991^{16}$, mantendo de certa forma silêncio sobre a violência sofrida perante o regime militar implantado em 1964 ${ }^{17}$, que lhe havia caçado o direito de sair do país (Pereira, 1994, p. 253).

Em seu depoimento, Pereira enfatiza que, em sua opinião, Schaden era "o homem mais internacional que havia entre nós. Tinha muito prestígio na América Latina. Quando se aposentou, ia de universidade em universidade como professor visitante, pois falava fluentemente alemão, inglês, francês, guarani e espanhol" (Marras, 2003, p. 331). E acrescenta:
14 Trata-se da obra Aspectos Fundamentais da Cultura Guarani publicada originalmente em 1954 reeditada em 1962 e 1974 no Brasil, sendo posteriormente publicada em outros idiomas (Meliá, S.J., 1991, p. 77). Outra obra, organizada por Hartmann e Coelho (1981), faz demonstração no mesmo sentido.

15 Pereira esclarece: "Schaden dava aula metade do ano aqui noBrasile metade do ano na Universidade de Bönn" (Marras, 2003, p. 326). E acres centa: "Uma tarde, depois que eu havia depositado a tese para defesa, Schaden nos reuniu e, sem avisarninguém, disse que havia acabado de tomar a decisão de se aposentar. [...] Schaden se aposentou imediatamente" (Marras, 2003).

16 Egon Schaden foi casado com Margarida Salf, procedente da Alemanha, com quem teve três filhos

17 Meliá, S.J. (1991, p. 77) refere-se ao "[... silêncio de uma jubilação forçada [...]", o que não o impediu de pesquisare refletir sobreacultura guarani até sua morte. 
18 O Museu de São Bonifácio guarda coleção de artefatos indígenas que atesta ointeressedeFrancisco Schaden por esse temaequecertamente exerceu influência sobre as escolhas de Egon no futuro.

19 Hilda Felipe reconhece a contribuição de Egon na formação continuada do pai quando aponta a existência de diálogoe troca de material bibliográfico entre os dois.

20 Thecla, uma dasirmãs mais jovens de Egon, informa em seu depoimento que outro irmão teve a oportunidade de estudar no mesmo Ginásio Catarinense em Florianópolis, dessafeita por iniciativa do pai. O irmão, no entanto, nãoconseguiuacompanhar os estudos e retornou ao trabalho na agricultura.
"Ele não era de esquerda nem de direita. Era alemão, simplesmente. Isto é muito difícil de explicar. $\mathrm{O}$ fato é que ele gerava enorme ambiguidade entre os alunos, porque estes eram muito fascinados pela esquerda. E Schaden era um homem que não se envolvia com questões político-ideológicas. Seu compromisso era com a antropologia" (Marras, 2003, p. 332).

Como demonstração cabal da influência e importância de Egon Schaden no universo da antropologia, Pereira afirma que nunca havia pensado em ser antropólogo e que havia ido à USP para cursar sociologia. A mudança de rumo ocorreu "[...] quando eu assisti a uma aula de Schaden sobre populações pigmeias da África Equatorial, minha nossa, eu saí antropólogo. Schaden me converteu" (Marras, 2003).

\section{ALGUMAS CONSIDERAÇÕES}

Gilbert Durand, na obra mencionada, mostra como o conteúdo do mundo real é acionado através da eficácia do imaginário, ou seja, pelas construções do espírito. O imaginário social é construído dentro de um universo de possíveis significados, em que o sentido dos fatos possui características dinâmicas. Afirma ainda esse autor que as representações coletivas são um componente do tecido do imaginário social. Na sua Teoria Geral do Imaginário, Durand busca a possibilidade de integração entre imaginário e razão.

Os elementos arrolados, que buscam atender à possibilidade levantada por Durand, tratam de dar conta do processo de colaboração científica entre Francisco e Egon Schaden, embora isso não seja explicitado nas obras consultadas. No caso da contribuição de Francisco Schaden na obra de Emílio Willems, não há como se pensar essa colaboração sem a intervenção do próprio Egon. Esses elementos, no entanto, não integram o imaginário de São Bonifácio, e sua ausência permite a disseminação e a permanência de outras racionalizações.

Decorridos vinte anos da morte de Egon Schaden, muito ainda falta ser esclarecido tanto sobre sua trajetória pessoal quanto sobre sua produção científica. No imaginário de São Bonifácio, no entanto, pode-se notar sem esforço que a figura de Francisco Schaden é destacada como sendo portadora de maior relevância. Alguns informantes afirmam que Egon, depois que saiu do lugar para estudar em Florianópolis e posteriormente em São Paulo, nunca mais regressou. Essa ideia é contrariada por seus parentes, como sua irmã Thecla, que registra as visitas anuais de Egon à família. Segundo ela, ele era "o Papai Noel da família. Todo Natal aparecia com um monte de presentes". Essa presença, no entanto, não foi suficiente para lhe dar posição de destaque no imaginário do lugar, o que é confirmado pelo depoimento de Hilda Felipe, da mesma geração de Egon e que conviveu com ele quando criança, quando afirma que "Egon não é muito conhecido por aqui" - embora isso signifique apenas que não é tido como um dos expoentes da história do lugar, papel reservado ao seu pai, o professor Schaden.

A cooperação científica entre pai e filho, no entanto, garantiu ao autodidata Francisco Schaden um lugar na antropologia. Se por um lado o pai pode ter exercido influência na escolha temática do filho pela questão indígena $^{18}$, o filho retribuiu levando a produção científica do pai para congressos e publicações de alcance nacional ${ }^{19}$.

A cena em que o menino Egon Schaden aparece limpando os sapatos do governador Adolfo Konder compõe uma espécie de "mito de origem" narrado reiteradamente pelos portadores da memória de São Bonifácio. A narrativa enfatiza o preço da grandeza alcançada pelo cientista Egon Schaden, mas ritualmente trata de atualizar, para os não iniciados nas coisas de São Bonifácio, o lugar social de onde emergiu o grande antropólogo. Mais que isso, a narrativa atenta para o fato de que, sem a mesma oportunidade viabilizada a Egon ${ }^{20}$, seus irmãos cumpriram um destino bem diferente, permanecendo em São Bonifácio e construindo suas vidas nas condições objetivas oferecidas por um universo camponês, como retrata o documentário Egon, Meu Irmão (Navi/Nepi, 2007) acerca dos irmãos de Egon. 


\section{BIBLIOGRAFIA}

CASTORIADIS, Cornelius. A Instituição Imaginária da Sociedade. Rio de Janeiro,

Paz e Terra, 1993.

DELEUZE, Gilles. Conversações. Rio de Janeiro, 34, 1992.

DURAND, Gilbert. As Estruturas Antropológicas do Imaginário. São Paulo, Martins Fontes, 1997.

HARTMANN, Tekla \& COELHO, Vera Penteado (orgs.). Contribuições à Antroplogia em Homenagem ao Professor Egon Schaden. São Paulo, Edusp, 1981.

JOCHEM, Toni Vidal. A Formação da Colônia Teresópolis e a Atuação da Igreja Católica (1860-1910). Dissertação de mestrado. PPGH/UFSC. Florianópolis, 2002.

JOCHEM, Toni Vidal. "Professor Francisco Schaden", in Revista Ágora, ano VII, n. 15. Florianópolis, jul. 1992, pp. 16-19.

MARRAS, Stélio. "Pessoa e Instituição - Entrevista com João Batista Borges Pereira", in Revista de Antropologia, v. 46, n. 2, 2003, pp. 319-45.

MARTINI, George; GARCIA, Ronaldo (orgs.). Os Impactos Sociais da Modernização Agrícola. São Paulo, Caetés, 1987.

MELIÁ, S.J., Bartolomeu. "Egon Schaden: um Nome na Etnologia Guarani", in Revista USP, n. 13. São Paulo, CCS-USP, mar.-abr.-mai./1992, pp. 74-7.

NAVI/NEPI. Egon, Meu Irmão. Florianópolis, Navi/Nepi/UFSC, 2007 (documentário).

PAULI, Evaldo. "Esperanto em Santa Catarina", in Congresso Universal de Esperanto. Fortaleza, 3 a 10/8/2002.

PEREIRA, João Baptista Borges. "Emílio Willems e Egon Schaden na História da Antropologia", in Estudos Avançados, 8(22), pp. 249-53, 1994.

RIBEIRO, Gustavo Lins. "Depoimento", in Revista de Antropologia, v. 46 n. 2, 2003, pp. 351-356.

SANTOS, Sílvio Coelho dos. "A Antropologia em Santa Catarina", in Memória da Antropologia no Sul do Brasil. Florianópolis, Edufsc/Aba, 2006, pp. 14-77.

SCHADEN, Egon (org.). Homem, Cultura e Sociedade no Brasil. Petrópolis, Vozes, 1972.

SCHADEN, Francisco. "Notas sobre a Localidade de São Bonifácio", in IX Congresso Brasileiro de Geografia. Florianópolis, 1940.

"A Pacificação e a Aculturação dos Xokléng", in Revista de Antropologia, v. 1,

n. 2, 1953, pp. 136-9.

“Xokléng e Kaingáng", in Revista de Antropologia, v. 6, n.2, 1958, pp. 105-12.

Índios, Caboclos e Colonos. São Paulo, FFLCH-USP, 1963.

SEYFERTH, Giralda. "A Colonização Alemã no Brasil: Etnicidade e Conflito", in Boris Fausto

(org.). Fazer a América. São Paulo, Edusp, 1999, pp. 273-313.

WILLEMS, Emílio. A Aculturação dos Alemães no Brasil. São Paulo, Edusp, 1980. 